\title{
THE NUMERICAL SIMULATION APPLICATION FOR FIRE-TUBE BOILER HEATING SURFACE SAFETY EVALUATION
}

\author{
Sergei A. Khaustov ${ }^{1, *}$, Olga V. Guk ${ }^{1}$, and Artem Lisenkov ${ }^{1}$ \\ ${ }^{1}$ National Research Tomsk Polytechnic University, 634050 Tomsk, Russia
}

\begin{abstract}
The numerical simulation is applied for fire-tube boiler heating surface safety estimation. Thermal processes in an inflatable fire-tube furnace during its emergency operation were simulated using the finite volume method with Euler approximation and the implicit pressure based algorithm. Study results reproduce failures connected with increasing of impasse aerodynamic resistance. The method of these failures prediction is suggested. Simulation has shown that entering the amount of coolant into combustion volume results in burner fan incapability to overcome the impasse resistance of the furnace. The simulation results are visually confirmed during the inspection of emergency boilers.
\end{abstract}

\section{Introduction}

Fire-tube boilers have a number of advantages over water-tube, but at the same time requiring more careful attitude in the design, manufacture, installation and operation [1]. The design of fire-tube boilers and their essential parts must ensure reliability and safety of operation. The main indicators are reliability, retentive durability, maintainability. Reliability is provided during the design, construction, operation and maintenance. Mistakes made at any stage, may negate the material resources, labour costs and time spent on all other stages.

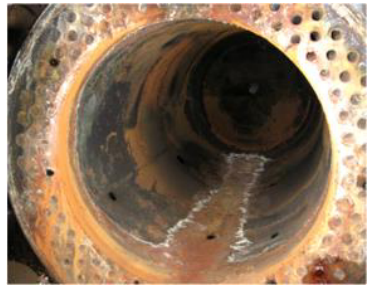

Fig. 1. The example of fire-tube boiler state after several years of operation.

In the case of feasibility studies, fire-tube boilers are used for non-project fuel burning such as waste oil, crude oil, and other sub-standard fuels [2]. After a certain service firetube boilers installed in some domestic and autonomous sources of heat were prone to

* Corresponding author: khaustovsa@tpu.ru 
corrosion. Sometimes this led to the emergency mode: the volume of the combustion chamber was littered with water stains, leakages were observed in the welds (fig. 1), there also were cracks in the tube plates and fire-tube surface bulges. In addition, elements of charred insulation were observed at the boiler cover.

Engineering design of fire-tube boiler has no unified regulatory framework [3]. Due to the lack of a uniform methodology for the construction of fire-tube boilers the numerical simulation method (NSM) is increasingly used. Benefits of NSM are expressed in the possibility of obtaining almost realistic picture of the combustion flow in the boiler, depending on the design and operation mode, which gives grounds to refute or confirm the structural decisions $[4,5]$. This method is used to investigate failures by simulating the conditions present during the incident. By NSM the further operational reliability of the boiler equipment in a certain period can be evaluated and set the necessary actions for the extension of the whole complex devices life [4 - 6].

\section{NSM of heating surfaces safety review}

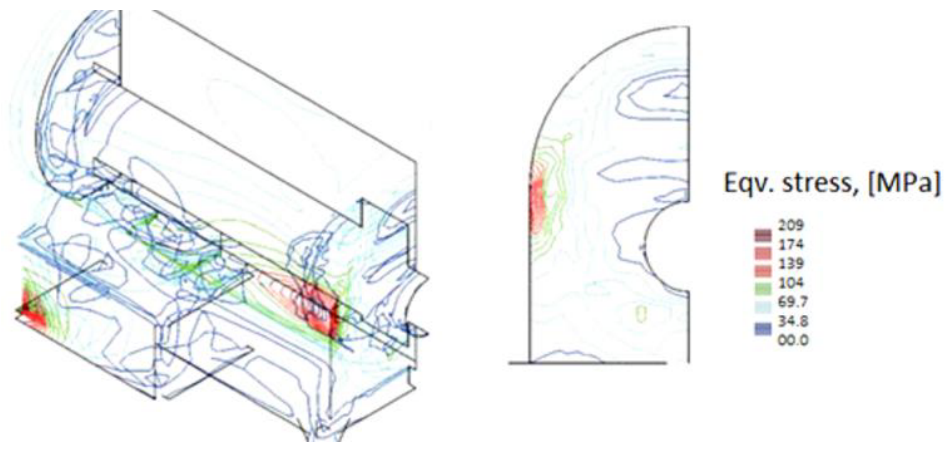

Fig. 2. The stress field of plating and the rear wall [7].

Computational and experimental analysis was carried out of the strength of the fire-tube boiler design by numerical simulation using the finite element method (FEM) in order to determine the need to consider the value of thermal stresses in fire-tube boiler design [7].

Table 1. Distribution of potential and kinetic energy of deformation [7].

\begin{tabular}{|c|c|c|c|c|c|c|}
\hline & \multicolumn{2}{|c|}{$\mathrm{f}_{01}=21 \mathrm{~Hz}$} & \multicolumn{2}{|c|}{$\mathrm{f}_{02}=33.3 \mathrm{~Hz}$} & \multicolumn{2}{|c|}{$\mathrm{f}_{03}=45.6 \mathrm{~Hz}$} \\
\hline & $\mathrm{E}_{\Pi}$ & $\mathrm{E}_{\mathrm{K}}$ & $\mathrm{E}_{\Pi}$ & $\mathrm{E}_{\mathrm{K}}$ & $\mathrm{E}_{\Pi}$ & $E_{K}$ \\
\hline Fire tube & 0.8 & 19.2 & 38.6 & 9.0 & 0.6 & 0.8 \\
\hline $\begin{array}{l}\text { Back recirculation } \\
\text { chamber and } \\
\text { inspection orifice }\end{array}$ & 0.6 & 7.0 & 34.4 & 73.4 & 1.0 & 1.1 \\
\hline $\begin{array}{l}\text { Boiler shell, } \\
\text { composed of housing } \\
\text { head }\end{array}$ & 46.8 & 25.6 & 9.1 & 0.6 & 95.0 & 95.6 \\
\hline Back head & 7.2 & 2.4 & 11.5 & 16.4 & 0.8 & 1.0 \\
\hline $\begin{array}{l}\text { Front head with front } \\
\text { recirculation } \\
\text { chamber }\end{array}$ & 0.2 & 16.0 & 2.0 & 0.3 & 1.2 & 0.7 \\
\hline Lugs & 44.4 & 29.8 & 4.4 & 0.3 & 1.4 & 0.8 \\
\hline
\end{tabular}


On the basis of the numerical model fire-tube boiler various parameters strength diagnostics were estimated. Membrane bending stress and strain energy distribution were considered as key criteria for identifying weakness in the design of the boiler.

Based on the research results presented (fig. 2 and table 1) it can be concluded that the boiler shell is an element with the highest concentrations of maximum stress and strain energy. A critical area is the design of the rear wall (fig. 2). Maximum stresses in the structure appear in the boiler drum near the junction of the rear wall (209 MPa). But it does not exceed the yield stress (215 MPa) for this element of material P265GH [8] (russian analogue $20 \mathrm{~K}$ steel).

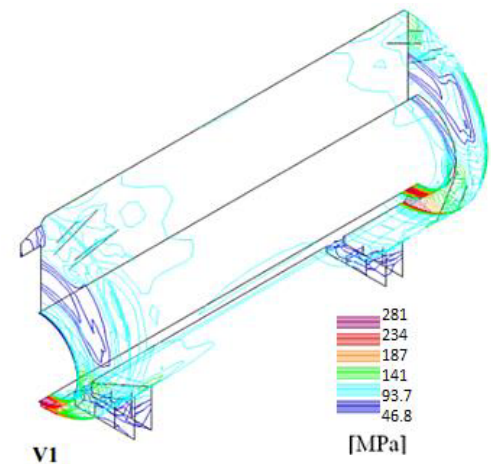

V1

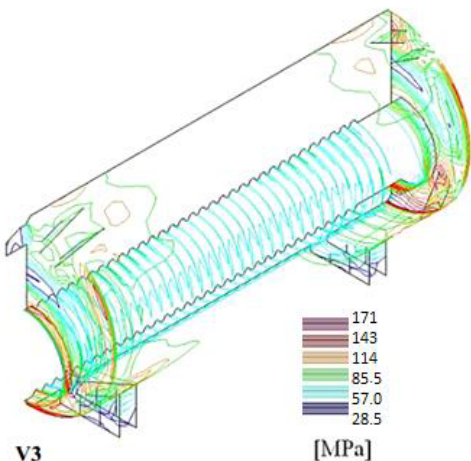

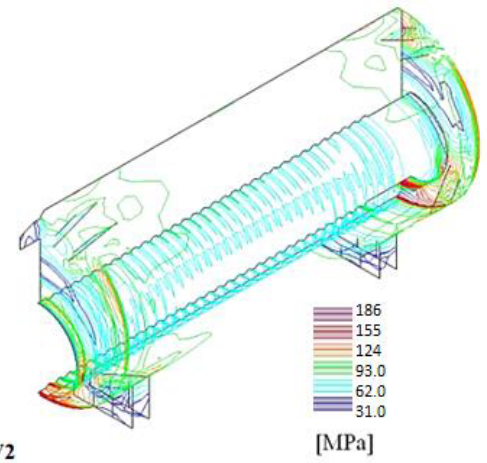

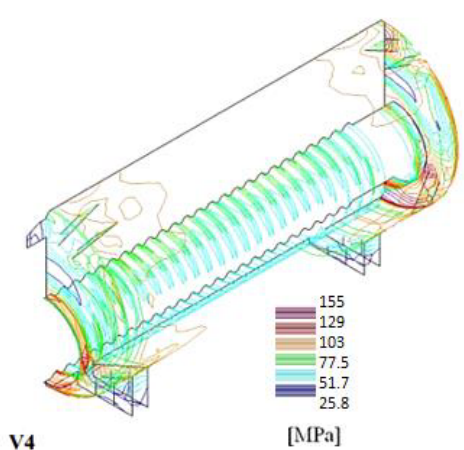

Fig. 3. The stress field models [9].

In [9] the influence of the form of the furnace tube of fire-tube boiler thermal deformation by NMS and FEM is estimated. Four fire-tube furnaces were investigated (fig. 3):

- V1 with smooth shape of the combustion chamber;

- V2 corrugations with a step equal to $151 \mathrm{~mm}$ and a depth of - $50 \mathrm{~mm}$;

- V3 increments - $151 \mathrm{~mm}$ and depth - $75 \mathrm{~mm}$;

- V4 c spacing of $200 \mathrm{~mm}$ and a depth of $75 \mathrm{~mm}$.

In the model, the maximum stress V1 equal to $281 \mathrm{MPa}$, are located at the junction of the furnace and the boiler casing. The maximum value is higher stresses than the yield strength of the material components, which is $211 \mathrm{MPa}$ for the material P295GH fire tube (analogue - 18K steel) and $187 \mathrm{MPa}$ for the material P265GH shell [8]. The maximum stress in the elements of the models with a corrugated furnace takes place in the model V2, and the value is $186 \mathrm{MPa}$, which is comparable to the yield strength of the material. V4 model has the smallest value of stress equal to $155 \mathrm{MPa}$. 
Table 2. Maximal deformations and stresses in the boiler substructures [9].

\begin{tabular}{|c|c|c|c|c|c|c|}
\hline \multirow{3}{*}{$\begin{array}{l}\text { Boiler } \\
\text { model }\end{array}$} & \multicolumn{3}{|c|}{ Pressure loads } & \multicolumn{3}{|c|}{ Thermal loads } \\
\hline & \multirow{2}{*}{$\begin{array}{c}\text { Maximal } \\
\text { deformation } \\
{[\mathrm{mm}]}\end{array}$} & \multicolumn{2}{|c|}{ Maximal stress [MPa] } & \multirow{2}{*}{$\begin{array}{c}\text { Maximal } \\
\text { deformation } \\
{[\mathrm{mm}]}\end{array}$} & \multicolumn{2}{|c|}{ Maximal stress [MPa] } \\
\hline & & $\begin{array}{c}\text { Furnace } \\
\text { tube }\end{array}$ & $\begin{array}{l}\text { Boiler } \\
\text { body }\end{array}$ & & $\begin{array}{c}\text { Furnace } \\
\text { tube }\end{array}$ & $\begin{array}{l}\text { Boiler } \\
\text { body }\end{array}$ \\
\hline V1 & 4.19 & 70 & 136 & 7.91 & 240 & 240 \\
\hline $\mathrm{V} 2$ & 5.66 & 85 & 135 & 7.37 & 134 & 134 \\
\hline V3 & 9.77 & 105 & 135 & 7.30 & 80 & 80 \\
\hline V4 & 10.50 & 111 & 135 & 7.30 & 84 & 84 \\
\hline
\end{tabular}

Based on the results (table 2) got by authors [9] the maximal stress caused by pressure in the boiler with a smooth furnace design is almost twice lower than in the corrugated furnace at higher stresses caused by the thermal loads. This suggests that the corrugated combustors have greater flexibility during thermal loading.

Based on the review it can be concluded that the use of numerical simulation of combustion processes in the fire tube boilers is necessary to assess the reliability of the heating surfaces. It is used to identify critical areas and shortcomings in the design of the boiler unit; discover the causes of unstable operation; reproduce the output process of equipment failure; determine the source of an emergency. But at the same time authors failed to find any information about NSM of emergency modes connected with increasing of impasse aerodynamic resistance for example caused by the one of following issues: wrong burner, wherein its design does adjust the correct flame geometry, and entering the coolant into combustion volume.

\section{Simulating the Emergency Mode}
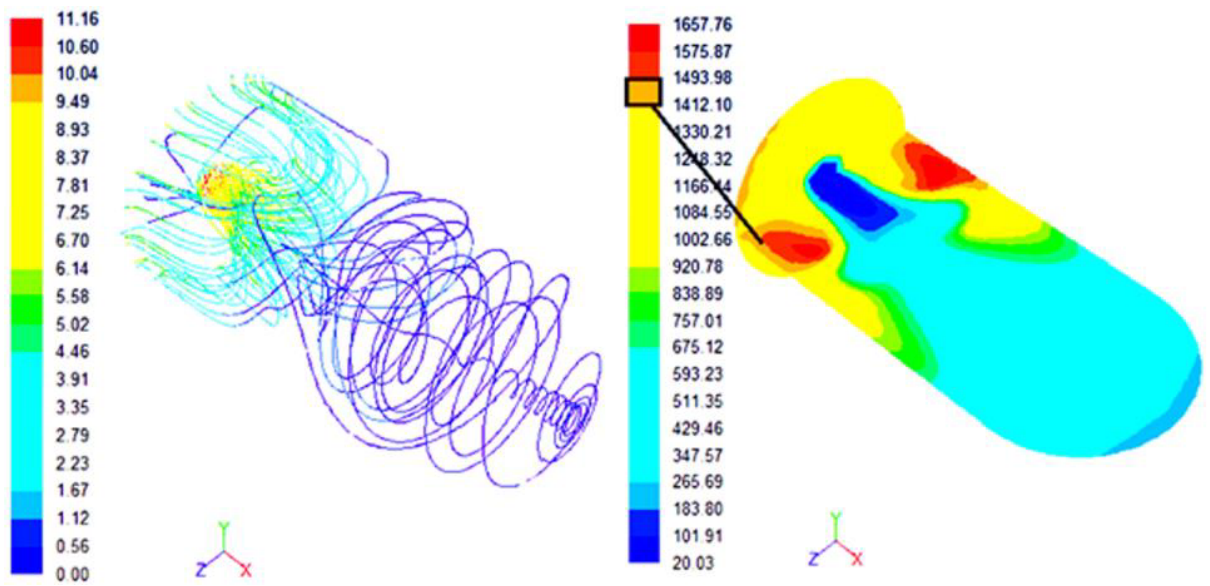

Fig. 3. Boiler in emergency mode: pathlines $(\mathrm{m} / \mathrm{s})$ and mean temperature contours $\left({ }^{\circ} \mathrm{C}\right)$.

The aim of this paper is to simulate thermal processes in an inflatable fire-tube furnace during the emergency mode connected with increasing of impasse aerodynamic resistance in order to diagnose and predict complex defects of boiler heating surfaces. Authors discuss the following failures: wrong burner, which does not allow adjusting the correct flame geometry, and an increasing of impasse aerodynamic resistance caused by entering the 
coolant into combustion volume. Both failures result in burner incapability to overcome the resistance of the furnace.

To simulate this emergency mode, the furnace plating considered to have leakages in the welds allowing water (coolant) getting into combustion volume. Water entering flaming furnace volume through the cracks almost instantly vaporises. According to the saturated steam table, vaporizing water 1672-fold expands resulting in the fan incapability to overcome the impasse aerodynamic resistance.

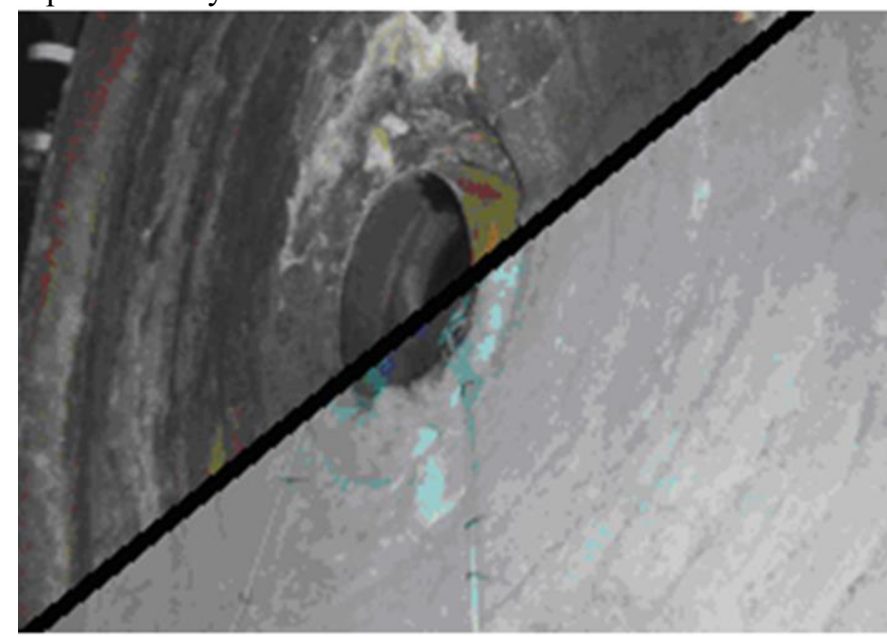

Fig. 4. Burned up cover insulation (pictured left) against the initial state (pictured right).

NSM of emergency mode indicates the sophisticated vortex motion within the impasse. High backpressure causes the formation of a stagnant zone filled by vaporised leaked water (fig. 4). Inertia of steam leakages provokes formation of asymmetric vortex twisting in furnace impasse $[10,11]$. Such highly twisted aerodynamics caused by high impasse gasdynamic resistance intensifies burning and increases the temperatures in the immediate vicinity of the burner [10]. As a result, the combustion takes place near the boiler front (fig. 4) and leads to high cover platting thermal stresses: the flame before blowing into the convection pipes comes into contact the insulation [10]. In this way insulation is burned during the boiler operation (fig. 4).

\section{Discussions and Conclusion}

Using the numerical simulation method, a processes of boiler emergency operation with fan incapability to overcome the fire tube resistance are visually represented. Authors of paper [10] describe an impasse aerodynamic resistance increasing due to wrong burner selection, this paper detects the same symptoms occurring, if the amount of coolant enters the combustion volume.

The simulation results are visually confirmed during the inspection of emergency boilers. Charred insulation of the boiler cover (fig. 4) visually demonstrates an excessive backpressure at the fire tube impasse. Together with the fact that the heat absorption of fire tube is reduced, the exhaust gases temperature increases, resulting in boiler efficiency reducing down to $89 \%$. Thermal losses connected with heat transfer to the environment through the boiler insulation also rise. After insulation cover is burned up (fig. 4) boiler efficiency will fall sharply. Furthermore, excessive thermal loads lead to burnouts of the tube sheet including weld ruptures caused by thermal expansion. 
Analysis of the obtained temperature contour concludes that aerodynamic resistance enlargement due to wrong burner selection or the coolant entering the combustion volume can be diagnosed at early stages by controlling the boiler cover temperature.

\section{Acknowledgments}

The reported study was partially supported by the Ministry of education and science of The Russian Federation, state order No. 13.948.2014/K.

\section{References}

1. Historical Advancement of Fire-Side Heating Surface in Fire-Tube Boilers, American Boiler Manufacturers Association (Arlington, Va., USA, 2004)

2. S.V. Dolgov, E.K. Savchenko, S.A. Khaustov, R.B. Tabakaev, A.S. Zavorin, EPJ Web Conf. 110, Article Number 01074 (2016)

3. S.A. Khaustov, A.S. Zavorin, K.V. Buvakov, N.A. Zakharushkin, MATEC Web Conf. 19, Article Number 01020 (2014)

4. R. A. Visloguzov, R. B. Tabakaev, A. S. Zavorin, S. V. Dolgov, K. I. Klochko, International Conference on Mechanical Engineering, Automation and Control Systems (TPU, Tomsk, Russia), 6986943 (2014)

5. R.B. Tabakaev, P.S. Gergelizhiu, A.V. Kazakov, A.S. Zavorin, IOP Conf. Series: Mate. Sci. Eng. 66, Article Number 012052 (2014)

6. S. A. Khaustov, E. I. Maksimova, International Conference on Mechanical Engineering, Automation and Control Systems (TPU, Tomsk), 7414903 (2015)

7. B. Gaćeša, V. Milošević-Mitić, T. Maneski, D. Kozak, J. Sertić, Technical Gazette 18, $1(2011)$

8. Flat products made of steels for pressure purposes. Non-alloy and alloy steels with specified elevated temperature properties (European standards, EN 10028-2: 2003)

9. B. Gaćeša, T. Maneski, V. Milošević-Mitić, M. Nesterović, A. Petrović, Thermal science 18, 1 (2014)

10. A.S. Zavorin, S.A. Khaustov, N.A. Zaharushkin, IOP Conf. Series: Mate. Sci. Eng. 66, 1, Article Number 012029 (2014)

11. S.A. Khaustov, A.S. Zavorin, K.V. Buvakov, L.D. Kudryashova, A.V. Tshelkunova, EPJ Web Conf. 82, Article Number 01041 (2015) 